\title{
Understanding trends and changes in media coverage of nanotechnology in India
}

\author{
Manish Anand*, N. Deepa ${ }^{1}$ \\ Science, Technology and Innovation Area, Green Growth and Development Division, ${ }^{1}$ Knowledge Management Division, \\ The Energy and Resources Institute, New Delhi, India
}

\begin{abstract}
The paper makes a first systematic study of the media coverage about nanotechnology in India. It investigates the key research question: How is nanotechnology presented in the news media? The number and content of nanotechnology-related articles in the news media indicates the general trend of limited science communication-related activities and a techno-centric focus.
\end{abstract}

Keywords: India, nanotechnology and media, newspapers and websites, periodicals

\section{INTRODUCTION}

Nanotechnology refers to a set of technology-platforms whose common aim is to exploit the unique properties of matter at the nanometer scale (one billionth of a meter) that are not displayed at a larger scale, for scientific research and commercial innovation creation. As nanotechnology-related activity has gained momentum and its applications have begun to appear in products, media coverage of nanotechnologies has increased.

Media coverage of an emerging issue plays an important role in making the issue more prominent in the collective mind of the publics. ${ }^{[1]}$ Research shows that the way message is framed in the news media plays an important role in influencing public preferences regarding political issues. ${ }^{[2]}$ Gamson and Modigliani in their half a century study on societal debate on the use of nuclear power has proved that characterizing the causes and likely consequences of

*Address for correspondence:

E-mail: manand@teri.res.in

\begin{tabular}{|c|c|}
\hline \multicolumn{2}{|c|}{ Access this article online } \\
\hline Quick Response Code: & \\
\hline \multirow{2}{*}{ 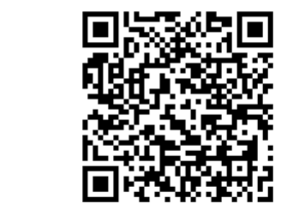 } & $\begin{array}{l}\text { Website: } \\
\text { www.jscires.org }\end{array}$ \\
\hline & $\begin{array}{l}\text { DOI: } \\
10.4103 / 2320-0057.115875\end{array}$ \\
\hline
\end{tabular}

a news story can have a great influence on establishing criteria for evaluating remedies and influencing public opinion. ${ }^{[3-5]}$

There are studies exploring these effects in the context of nanotechnology such as, studies on scientists' views on nanotechnology reporting, ${ }^{[6]}$ the framing of concepts important to nanotechnology by scientists and other agents, ${ }^{[7,8]}$ the framing of risks, ${ }^{[9]}$ and multiple content analyses of newspaper coverage of nanotechnology, ${ }^{[10-14]}$ in order to understand who is setting the debate, how they are setting it, and what topics are being debated. In their in-depth study, Kahan et al. ${ }^{[15]}$ shows that public perception on risks and benefits regarding nanotechnology is being guided less by factual knowledge and more by their affective or emotional responses to it.

Research work in this area in the recent years has focused on investigating more nuanced or complicated aspects of the issue, like how the trust of audience in a source impacts the reception of a framed message ${ }^{[16]}$ and how audience frame reception in the presence of many competing frames. ${ }^{[17]}$

Against the above backdrop, the paper explores the coverage of nanotechnology in the news media in India. It investigates the following key research questions: How is nanotechnology presented in the news media? In the course of time, have there been changes in the scale of 
reporting and how can they be explained? Which topics and interpretation frames are found in media coverage?

These questions were examined using systematic, standardized content analysis of articles gathered from selected periodicals and newspapers and websites based on nanotechnology-related search terms [Table 1]. The data set encompassed articles published during the five year period from 2007 to 2011 . The number of articles published in the data set were counted and recorded with respect to the focus area of each article.

\section{ANALYSIS AND DISCUSSION}

\section{Coverage Trends and Patterns}

In the Indian scenario, in general, science and technology coverage in the news media is fairly low. This is also observed in the case of emerging areas of science and technology like nanotechnology. During the study period, an average of 114 nanotechnology-related articles per year across all the data sources has been observed. However, there has been a declining trend in the coverage of nanotechnology-related news in the media during 2007 to 2011. Greater coverage in the beginning could be attributed to the fact that the Government of India launched a Mission on Nano Science and Technology (Nano Mission) in May 2007, in which an allocation of INR 1000 crores ((US\$ 254 million) for 5 years has been made. The initial excitement with regard to the prospects and potential of this technology and the policy thrust garnered media attention, which eventually showed a declining trend in due course of time.

Figure 1 show results of the analysis of nano science and technology-related reporting under various themes. During the years 2007 to 2011, media coverage has been more in the areas of Applications of nanotechnology in sectors;

- Research developments and collaborations;

- Capacity development (developments about new courses being offered by universities and recent and forthcoming conventions/conferences/seminars).

In general, there has been a declining trend in the news article coverage of issues related to government policies and guidelines while the applications of nanotechnology in various sectors has been adequately covered in the media during the study period. As can be seen in Figure 1, scientific discoveries or projects have been the most dominant context for nano science and technology reporting in India while social implications and risks were relatively less common.

\section{Application Domains Found in Articles}

Figure 2 depicts the number of articles related to various nanotechnology application domains in the news media during the study period. As can be seen in Figure 2, there has been high coverage of nanotechnology applications in the news media in India, particularly in the sectors of health, energy, food security, water, and information and communications technology (ICT). Several industry-related sectors like pharmaceuticals, electronics, ICT as well as biotechnology appear poised to gain from nanotechnology applications. As illustrated in Figure 2, nanomaterials and

\begin{tabular}{|c|c|c|c|}
\hline \multirow{2}{*}{$\begin{array}{l}\text { Analytical } \\
\text { period }\end{array}$} & \multicolumn{2}{|c|}{ Source of information (print and online) } & \multirow[t]{2}{*}{ Search terms } \\
\hline & Periodical and Newspapers & Websites & \\
\hline \multirow{12}{*}{$\begin{array}{l}5 \text { years } \\
\text { (2007 to 2011) }\end{array}$} & Current Science & Nanowerk <http://www.nanowerk.com> & Nanotechnology \\
\hline & The Times of India & AZonano <http://www.azonano.com> & Nanoscience \\
\hline & The Economic Times & Nanotechnology Now <http://www.nanotech-now.com> & Nanomaterials \\
\hline & Hindustan Times & Nanotech web <http://nanotechweb.org > & Nanoparticles \\
\hline & The Financial Express & Nanotech Wire <http://nanotechwire.com/> & Nanotubes \\
\hline & Indian Express & SciDev <http://www.scidev.net/> & Nanoethics \\
\hline & The Hindu & India Education Diary <http://www.indiaeducationdiary.in/> & \\
\hline & The Hindu Business Line & $\begin{array}{l}\text { Nanotechnology and Development News <http://www.merid.org/en/Content/ } \\
\text { News_Services/Nanotechnology_and_Development_News/Articles.aspx }>\end{array}$ & \\
\hline & Business Standard & Business Wire India <http://www.businesswireindia.com> & \\
\hline & The Pioneer & Top News <http://www.topnews.in> & \\
\hline & The Statesman & PTI News <http://www.ptinews.com> & \\
\hline & The Tribune & $\begin{array}{l}\text { Other sources featured in Google News Alerts like PR Newswire, } \\
\text { MSN news, PRLog, EE Times, IBN Live, India PRWire, Silicon India, } \\
\text { Pharmabiz, India Infoline, Sify news, and others }\end{array}$ & \\
\hline
\end{tabular}




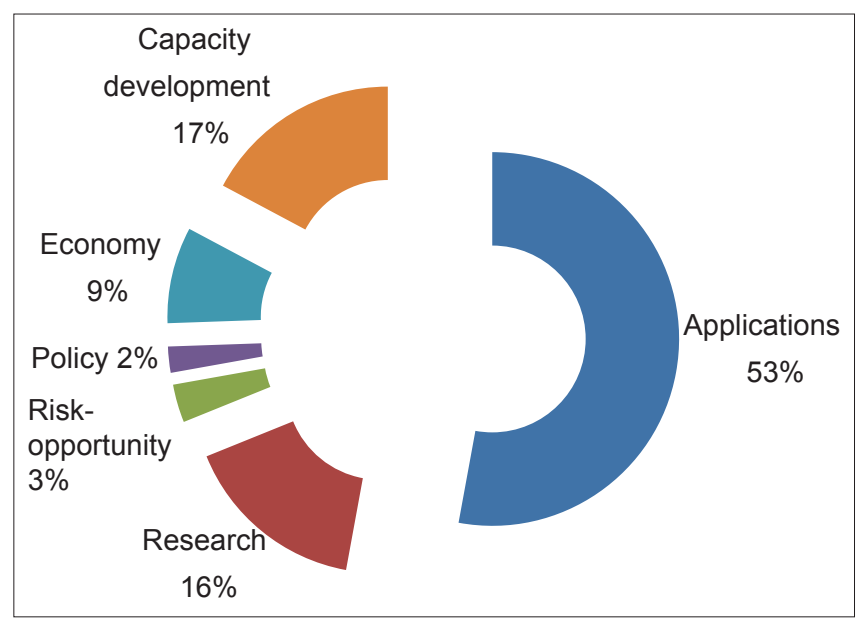

Figure 1: Percentage coverage of nanotechnology thematic areas in the news media*

*Data sample covers years 2007-2011. Total number of the articles in the sample is 574

nanotechnology-based health-related applications, which is a fast-growing sphere in India with both government and industry support, constitute the largest share (32\%) among nanotechnology application domains in the news media.

Content analysis among the application domains reveals that scientific progress and economic implications of nanotechnologies seem to gain strong interest. Consequently, the lure of using nanotechnology as a tool to enhance industrial competitiveness and national development in this globalised world has acquired widespread attention in the news media.

The study findings seems to reflect emphasis given on building the science and technology base around this technology, strengthening the skill set and harnessing the technology for meeting the development needs. Due to the emergent nature of the technology, research and development (R\&D) is being actively pursued by both public and private labs and institutions. $R$ and $D$ in scientific institutions, and public and private laboratories had been adequately covered in the news media. The training of human resource base in multidisciplinary aspects of this technology as well as the creation of interdisciplinary environments for $R \& D$ seems to have gained interest in the news media over the years. As these technologies require heavy investment and strategic planning at the national level, the role of government in directing investment and building capacity to successfully engage with this technology has been emphasized upon by the news media. This reflects the general trend prevailing in developing countries, which generally have restricted $\mathrm{S}$ and $\mathrm{T}$ capability and are unable

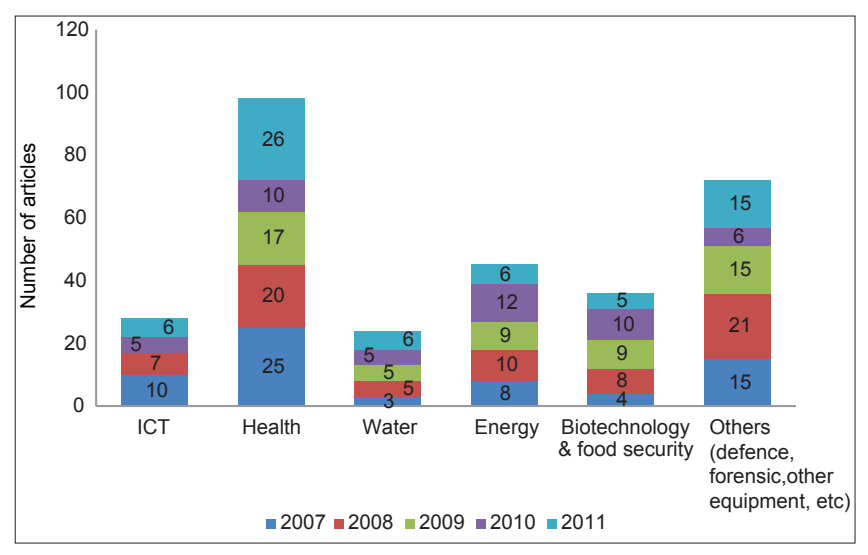

Figure 2: Number of articles related to nanotechnology application domains during the study period, 2007-2011* *Total number of the articles in the sample is 303

to engage in $\mathrm{R} \& \mathrm{D}$ in the manner of developed nations. Therefore, in order to strengthen the nation's science and technology resource, the policy making establishment appears to want to promote $\mathrm{R} \& \mathrm{D}$ in frontier science and technology including biotechnology, advanced materials, and nanotechnology. Content analysis of the news articles reveals the focus on the following dimensions of nanotechnology R\&D capacity building as the responsibility of national agencies and policy making-allocation of funds for nanotechnology development, establishment of institutions and centers for R\&D, facilitating technology development and industry participation, developing skilled human resources, forging national and international collaborations. Elsewhere, particularly in EU countries, it has been observed that greater media coverage of the social consequences of science has been influential in engendering public awareness and acceptance of new technologies. In the Indian case, the number and content of nanotechnology-related articles in the news media indicates the general trend of limited science communication-related activities and a techno-centric focus.

\section{ACKNOWLEDGEMENTS}

The paper has been developed under the project titled "Nanotechnology in South Asia: Building Capabilities and Governing the Technology," supported by International Development Research Center (IDRC), Canada.

\section{REFERENCES}

1. McCombs M. Setting the Agenda: Mass Media and Public Opinion. Malden: Blackwell; 2004.

2. Nelson T, Clawson R, Oxley Z. Media framing of a civil liberties conflict and its effects on tolerance. Am Polit Sci Rev $1997 ; 91: 567-83$ 
3. Gamson W. Talking politics. New York: Cambridge University Press; 1992.

4. Iyengar S. Is anyone responsible? Chicago: University of Chicago Press; 1991

5. Nelson T, Kinder T. Issue framing and group-centrism in American public opinion. J Polit Econ 1996;58:1055-78.

6. Petersen A, Anderson A, Allan S, Wilkinson V. Opening the black box: Scientists' views on the role of the news media in the nanotechnology debate. Public Underst Sci 2008;18:512-30.

7. Allan S, Anderson A, Petersen A. Framing risk: Nanotechnologies in the news. J Risk Res 2010;13:29-44.

8. Ebeling M. Mediating uncertainty: Communicating the financial risks of nanotechnologies. Sci Commun 2008;29:335-61.

9. Anderson A, Petersen A, Wilkinson C, Allan S. Nanotechnology, risk and communication. Houndmills: Palgrave Macmillan; 2009.

10. Anderson A, Allan S, Petersen A, Wilkinson C. The framing of nanotechnologies in the British Press. Sci Commun 2005;27:200-20.

11. Dudo A, Dunwoody S, Scheufele DA. The emergence of nano news: Tracking thematic trends and changes in U.S. newspaper coverage of nanotechnology. J Mass Commun Q 2011; 88:55-75.

12. Kjolberg K. Representations of nanotechnology in Norwegian newspapers-implications for public participation. Nanoethics 2009;3:61-72.

13. Stephens L. News narratives about nano $S$ and $T$ in major U.S. and Non-U.S. newspapers. Sci Commun 2005;27:175-99.

14. Weaver D, Lively E, Bimber B. News media tell the story of technological progress, risk, and regulations. Sci Commun 2009;31:139-66.

15. Kahan DM, Slovic P, Braman DA, Gastil J, Cohen G. Nanotechnology risk perceptions: The influence of affect and values. Cultural Cognition Project at Yale Law School and the Project on Emerging Nanotechnologies, Woodrow Wilson International Centre for Scholars; 2007. Available from: http://www.nanotechproject.org/ file_download/files/NanotechRiskPerceptions-DanKahan.pdf [Last accessed on 2012 Sep 20].

16. Druckman J. On the limits of framing effects: Who can frame? J Polit Econ 2001;63:1041-66.

17. Chong D, Druckman J. Framing public opinion in competitive democracies. Am Polit Sci Rev 2007;101:637-55.

How to cite this article: Anand M, Deepa N. Understanding trends and changes in media coverage of nanotechnology in India. J Sci Res 2013;2:70-3.

Source of Support: Nil, Conflict of Interest: None declared 